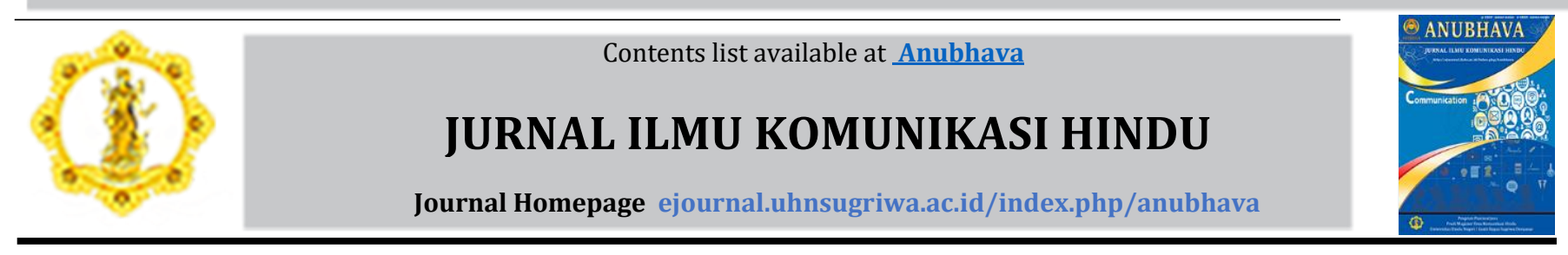

\title{
STRATEGI KOMUNIKASI INTERPERSONAL SALES DAN MARKETING DALAM MENINGKATKAN MINAT PELANGGAN DI HOLIDAY INN RESORT BALI BENOA
}

\author{
Desak Putu Oka Shinta Purnamayanti a,1 \\ I Gusti Ngurah Sudiana ${ }^{a}$ \\ I Gede Januariawan ${ }^{a}$
}

\author{
a Universitas Hindu Negeri I Gusti Bagus Sugriwa Denpasar \\ ${ }^{1}$ Corresponding Author, email: desakshinta94@gmail.com (Purnamayanti)
}

\section{ARTICLE INFO}

\section{Article history:}

Received: 21-01-2021

Revised: 19-02-2021

Accepted: 18-03-2021

Published: 31-03-2021

\section{Keywords: \\ Interpersonal \\ Communication \\ Strategy, Sales \\ Marketing, \\ Customers}

ABSTRACT

\begin{abstract}
Based on data from the Central Bureau of Statistics Bali Province in 2020 there was a decrease in the number of room occupancy in 5-star hotels, especially in Badung Regency. This is a challenge for a new five-star hotel that was established in 2015, namely the Holiday Inn Resort Bali Benoa. To increase customer visits, an interpersonal communication strategy is needed to attract customer interest and get feedback from customers. There are three problems in this research as follows: (1) How interpersonal sales and marketing communication strategies in attracting customers of Holiday Inn Resort Bali Benoa; (2) How is Holiday Inn Resort Bali Benoa customer feedback; (3) What are the advantages and disadvantages of sales and marketing of Holiday Inn Resort Bali Benoa. Theories used are communication planning theory, uncertainty reduction theory, and marketing communication theory. Data collection techniques were carried out by observation, interviews, and documentation. The technique of presenting data using qualitative descriptive. The results of this research are the interpersonal communication strategy of sales marketing, the need to determine goals, namely increasing visits, by planning and preparing offers such as paying attention to language selection, to offer products using media such as telephone, email, and social media to find customers. Reducing uncertainty for customers, sales marketing applies passive, active, and interactive strategies so that when a customer has visited the hotel, the hotel gets feedback through reviews available on the Website and online services. To support the increase in customers, marketing gives the offers by advertising, sales promotion, public relations and publicity, and personal selling. The advantages of this marketing are that it has detailed and communicative services and the weakness is in several offer still expensive and less negotiable offers
\end{abstract}

\section{PENDAHULUAN}

Pulau Bali terkenal dengan Pulau yang memiliki keberagaman adat istiadat, seni, dan budaya mampu menarik hati para wisatawan. Pesona yang begitu kompleks menjadikan para wisatawan tertarik mengunjungi Pulau Dewata ini yang dikenal sebagai salah satu destinasi terbaik di dunia. Pariwisata di Bali sangat ditunjang dengan adanya perhotelan yang menjadi tempat menginap para wisatawan. 
Berbagai hotel menawarkan akomodasi dan pelayanan terbaik untuk menarik minat pelanggan.

\section{Gambar 1}

TPK Pada Hotel Berbintang di Bali Menurut Kabupaten/Kota Desember 2019 dan Januari 2020

\begin{tabular}{clccc}
\hline & & \multicolumn{3}{c}{ Tingkat Penghunian Kamar (TPK) (\%) } \\
No. & Kabupaten/Kota & Desember 2019 & Januari 2020 & Perubahan (Poin) \\
\hline $\mathbf{1}$ & Badung & 63,98 & 60,57 & $-3,41$ \\
$\mathbf{2}$ & Gianyar & 52,78 & 57,43 & 4,65 \\
$\mathbf{3}$ & Karangasem & 40,19 & 38,17 & $-2,02$ \\
$\mathbf{4}$ & Buleleng & 39,88 & 39,56 & $-0,32$ \\
$\mathbf{5}$ & Denpasar & 62,43 & 58,91 & $-3,52$
\end{tabular}

Sumber: Badan Pusat Statistik Provinsi Bali Tahun 2020

Data Badan Pusat Statistik tahun 2020 menjelaskan bahwa telah terjadi penurunan pengunjung dibeberapa hotel berbintang di Bali termasuk hotel berbintang lima yang merupakan hotel dengan fasilitas mewah dan pelayanan istimewa. Adanya penurunan tersebut berdampak pada salah satu hotel yaitu Holiday Inn Resort Bali Benoa yang merupakan hotel bintang lima yang berusia belia berlokasi di kawasan Tanjung Benoa Nusa Dua.

Memajukan bisnis pariwisata di Bali juga tidak luput dari ajaran Agama Hindu yang berbasis Tri Hita Karana. Penetapan pengembangan pariwisata budaya sesuai dengan Peraturan Daerah Provinsi Bali Nomor 2 Tahun 2012 tentang Kepariwisataan Budaya Bali, yang berbunyi:

Kepariwisataan Budaya Bali adalah kepariwisataan Bali yang berlandaskan Kebudayaan Bali yang dijiwai oleh ajaran Agama Hindu dan falsafah Tri Hita Karana sebagai potensi utama menggunakan kepariwisataan sebagai wahana aktualisasinya, yang mewujudkan hubungan timbal-balik yang dinamis antara kepariwisataan dan kebudayaan yang membuat keduanya berkembang secara sinergis, harmonis dan berkelanjutan untuk dapat memberikan kesejahtraan kepada masyarakat, kelestarian budaya dan lingkungan (Pranata dkk, 2017)

Konsep Tri Hita Karana menjadi salah satu faktor untuk mencerminkan kearifan lokal yang menarik perhatian wisatawan. Hal ini dapat dijadikan sebagai startegi pemasaran bagi penggerak bisnis akomodasi perhotelan di Bali. Pentingnya komunikasi interpersonal yang dilakukan antara sales dan marketing kepada pelanggan sangatlah penting untuk dijaga. Adanya komunikasi yang berkesinambungan akan menciptakan interaksi yang baik antara sales dan marketing dengan pelanggan Holiday Inn Resort Bali Benoa. Menurut Suranto (2011: 5) komunikasi interpersonal atau komunikasi antarpribadi adalah proses penyampaian dan penerimaan pesan antara pengirim pesan (sender) dengan penerima (receiver) baik secara langsung maupun tidak langsung.

Menurut ajaran Agama Hindu komunikasi dan interaksi ini dalam tri kaya parisudha sebagai bentuk nyata dari manacika yaitu berpikir yang baik, wacika berkata yang baik, dan kayika merupakan berbuat yang baik dan kemudian diterapkan dalam kehidupan seharihari. Untuk kemudian, pola interaksi ini menjadikan bagian dari etika komunikasi dalam Veda yang ada dalam kehidupan modern (Suhardi dan Tantre, 2018: 75). Kenyataan dalam kehidupan untuk menjaga keselarasan 
hidup sehingga komunikasi dapat berjalan dengan baik maka diperlukan penerapan ajaran tri kaya parisudha sebagai pedoman.

Banyaknya kompetitor menyebabkan persaingan dalam dunia perhotelan di kawasan Nusa Dua semakin ketat. Menghadapi persaingan yang ketat seiring perkembangan minat pelanggan maka diperlukan strategi yang tepat untuk memecahkan permasalahanpermasalahan yang ada. Holiday Inn Resort Bali Benoa merupakan salah satu bagian dari Intercontinental Hotel Group, yang dikenal sebagai IHG. Khususnya bagi divisi sales dan marketing yang diharapkan mencapai target untuk meningkatkan kunjungan pelanggan. Sales dan marketing Holiday Inn Resort Bali Benoa memiliki berupa paket menginap, paket acara pernikahan (wedding event), dan penawaran untuk rapat. Teknik pemasaran yang telah dilakukan Holiday Inn Resort Bali Benoa yaitu teknik pull dan push yang merupakan teknik yang sudah berjalan sejak awal dibukanya hotel ini.

Untuk meningkatkan minat pelanggan maka diperlukan strategi lainnya yang dapat menunjang penjualan sales dan marketing. Upaya yang dapat dilakukan untuk meningkatkan pelanggan dengan menggunakan strategi komunikasi interpersonal yaitu teori perencanaan komunikasi. Menurut Berger (Budyatna, 2015: 91) rencana-rencana merupakan struktur-struktur pengetahuan hierarkis yang menggambarkan serangkaian tindakan tujuan yang terarah, sedangkan perencanaan merupakan proses yang menghasilkan sebuah rencana atau rencanarencana sebagai produknya. Perencanaan meliputi situasi, memutuskan tujuan atau tujuan-tujuan yang untuk dikerjakan, dan kemudian melaksanakannya. Sebagaimana proposisi-proposisi teori perencanaan berpendapat, pesan-pesan verbal dan nonverbal merupakan instrument yang individuindividu gunakan untuk mencapai tujuan-tujuan dalam kehidupan sehari-hari mereka.
Pertukaran-pertukaran pesan diantara orang memungkinkan mereka untuk mencapai tujuantujuan mereka.

Budyatna (2015: 89-91) menambahkan dalam bukunya yang berjudul karakteristik pendekatan teori perencanaan komunikasi berdasarkan rancana atau plan-based approach bagi komunikasi interpersonal yaitu sebagai berikut:

1. Tujuan yang diarahkan atau goal-directed

2. Pemuasan tujuan secara lebih efektif dan efisien

3. Penggunaan bahasa untuk mencapai tujuan-tujuan

4. Rencana dibuat untuk mencapai tujuan

5. Tujuan memiliki tingkatan hirearkis

6. Rencana-rencana juga memiliki tingkatan hirearkis

7. Perlu pemahaman tentang tujuan dan rencana (Norvica, 2018: 28)

Ketika melakukan komunikasi dengan pelanggan sales dan marketing tentu menghadapi kendala yang tidak terduga seperti ketidakpastian yang bersumber dari keputusan yang diberikan oleh pelanggan maka diperlukan teknik pemecahan masalah tersebut dengan teori pengurangan ketidakpastian. Teori Pengurangan Ketidakpastian atau Uncertainty Reduction Theory yang dicetuskan oleh Charles Berger. Berger menyatakan beberapa cara yang dapat dilakukan untuk mendapat informasi tentang orang lain yaitu melalui strategi pasif adalah pengamatan, sedangkan strategi aktif dengan mengharuskan pengamat untuk melakukan sesuatu untuk mendapatkan informasi, dan strategi interaktif sangat bergantung pada komunikasi dengan orang lain (Littlejohn, 2009: 219). Dengan mengetahui minat pasar dengan memperhatikan keperluan serta tujuan dari pelanggan maka dapat mengurangi ketidakpastian dari pelanggan.

Untuk dapat dikenal oleh masyarakat luas sales dan marketing dapat melakukan penawaran dengan teori komunikasi pemasaran. Kegiatan promosi merupakan salah satu bagian dari strategi pemsaran. Menurut Kotler (2005: 
264-312) mengatakan bahwa unsur bauran promosi (promotion mix) terdiri atas lima perangkat utama, yaitu :

1. Advertising atau periklanan merupakan semua penyajian non personal, promosi ideide, promosi produk atau jasa yang dilakukan sponsor tertentu yang dibayar.

2. Sales Promotion atau promosi penjualan yaitu berbagai insentif jangka pendek untuk mendorong keinginan mencoba atau membeli suatu produk atau jasa.

3. Public relations and publicity atau hubungan masyarakat berkaitan dengan berbagai program untuk mempromosikan dan/atau melindungi citra perusahaan atau produk individualnya.

4. Personal Selling atau penjualan perorangan adalah interaksi langsung dengan calon pembeli atau lebih untuk melakukan suatu presentasi, menjawab langsung dan menerima pesanan. (Widia: 2015: 32)

Berdasarkan masalah yang ada maka diperlukan penerapan strategi komunikasi interpersonal secara tepat, analisis tentang kelebihan dan kelemahan sales dan marketing untuk mengurangi ketidakpastian yang dapat ditimbulkan oleh pelanggan Holiday Inn Resort Bali Benoa. Hal ini bertujuan agar dapat bersaing dalam menarik minat pelanggan dengan hotel berbintang lima lainnya.

\section{METODE PENELITIAN}

Menurut Moleong penelitian kualitatif adalah penelitian untuk memahami fenomena dengan cara deskripsi dalam bentuk kata-kata dan bahasa, pada suatu konteks khusus yang alamiah dan dengan memanfaatkan berbagai metode alamiah (2005:6). Penelitian ini dilakukan di hotel Holiday Inn Resort Bali Benoa dalam waktu 2 bulan yaitu Bulan Juni hingga Agustus 2020. Sumber data yang diperoleh dibagi menjadi dua yaitu data primer yang bersumber dari dari karyawan sales dan marketing sedangkan data sekunder bersumber dari dokumen seperti literatur atau naskah akademik. Penelitian ini menggunakan teknik purposive sampling yang merupakan teknik pengambilan sampel sumber data dengan pertimbangan tertentu (Sugiyono 2008: 218). Pertimbangan tertentu ini misalnya orang tersebut yang dianggap paling tahu tentang apa yang peniliti harapkan, atau mungkin responden sebagai penguasa sehingga akan memudahkan peneliti menjelajahi obyek atau situasi sosial yang diteliti dan terdapat 3 responden yaitu Director of Sales and Marketing, Assistant Manager Reservation dan Bussiness Development Manager Leisure and Wedding offer. Teknik pengumpulan data dilakukan dengan observasi, wawancara, dan dokumentasi. Teknik analisis data yang digunakan yaitu pengumpulan data, reduksi data, penyajian data, dan penarikan kesimpulan serta penyajian hasil data berupa deskripsi kualitatif.

\section{HASIL DAN PEMBAHASAN}

Holiday Inn Resort Bali Benoa didirikan pada tanggal 01 April 2015 dan dimiliki oleh Surjantoro Siswantoro di bawah PT. Tanjung Benoa. Holiday Inn Resort Bali Benoa memiliki 171 kamar dengan berbagai pilihan tipe kamar mulai dari suite bertema superior, keluarga dan anak-anak, dan Premier Suite. Semua kamar dirancang dengan balkon sendiri dan tempat duduk outdoor untuk menikmati angin laut yang nyaman. Lokasi terletak di Jalan Pratama nomor 86, Tanjung Benoa, Kuta Selatan, Badung, Bali, Indonesia 80363. Pangsa pasar Holiday Inn Resort Bali Benoa adalah wisatawan domestik dan asing seluruh dunia (Eropa, Amerika, Afrika, Asia dan Australia). Untuk mencapai misi yaitu memenangkan hati pelanggan. Holiday Inn Resort Bali Benoa memiliki visi adalah menciptakan kenangan yang tidak terlupakan melalui interaksi personalisasi. Demi mewujudkan dan mencapai impian para pelanggan dengan kolaborasi yang bersinergi pihak manajemen menciptakan pengalaman otentik selama menginap di Holiday Inn Resort Bali Benoa untuk para pelanggan.

Strategi komunikasi interpersonal yang dilakukan oleh sales dan marketing Holiday Inn 
Resort Bali Benoa menggunakan perencanaan komunikasi yaitu: visi menciptakan kenangan yang tidak terlupakan melalui interaksi personalisasi sebagai tujuan, mengetahui minat serta kebutuhan pelanggan, penggunaan Bahasa Inggris dan Bahasa Indonesia yang bersifat persuasif, perencanaan yang pertama yang dilakukan adalah dengan memilih penawaranpenawaran yang cocok untuk dipasarkan sesuai target pasar, meningkatkan kunjungan pelanggan agar target tercapai, menciptakan relasi yang baik terhadap pelanggan, menunjukkan citra yang baik di masyarakat baik domestik dan mancanegara, pelanggan akan diberikan promo alternatif jika terjadi negosiasi berupa jika pemesanan kamar banyak akan diberikan complimentary, dan sales dan marketing memahami tujuan dalam pemasaran, memiliki karakter yang kuat dan menguasai product knowledge.

Adapun komponen komunikasi interpersonal dalam kegiatan penjualan sales dan marketing Holiday Inn Resort Bali Benoa adalah adanya komunikan yaitu sales dan marketing, penawaran dan promosi yang berupa paket acara pernikahan dan paket liburan waktu senggang bersama keluarga sebagai pesan yang akan disampaikan, adanya media sebagai perantara penyampaian pesan seperti facebook, instagram, dan twitter, terdapat komunikan yaitu pelanggan sebagai penerima pesan, dan adanya tanggapan berupa penilaian terkait dengan kinerja pihak manajemen Holiday Inn Resort Bali Benoa. Untuk menentukan penawaran yang diberikan sales dan marketing melihat segmentasi pasart berdasarkan umur untuk wanita dan pria yang rata-rata berusia 3070 tahun karena Holiday Inn Resort Bali Benoa dirancang dengan konsep keluarga maka hotel ini lebih memfokuskan penjualan pada orangorang yang sudah berkeluarga.

Saat melakukan penjualan sales dan marketing menghadapi tantangan salah satunya yaitu adanya ketidakpastian dari pelanggan dalam memberi keputusan untuk menggunakan akomodasi dan jasa yang ditawarkan. Maka diperlukan cara mengatasi ketidakpastian dengan tiga strategi pengurangan ketidakpastian seperti:

a. Strategi pasif yaitu sales dan marketing mengamati minat dari pelanggan itu sendiri baik melalui internet maupun berita lainnya.

b. Strategi aktif merupakan strategi sales dan marketing untuk mencari tahu mengenai situasi suatu negara dan karakter masyarakat disana.

c. Setelah memperoleh gambaran melalui pengamatan yang telah dilakukan oleh sales dan marketing selanjjutnya mulai menjalin interaksi secara langsung dengan pelanggan. Interaksi secara langsung merupakan bentuk strategi pengurangan ketidakpastian secara interaktif.

Upaya mengatasi ketidakpastian dapat dilakukan oleh sales dan marketing dengan menerapkan strategi dan mengetahui karakteristik calon pelanggan memberikan negosiasi dengan memberikan harga khusus atau penawaran khusus demi terjualnya akomodasi dan membangun citra yang menyenangkan bagi calon pelanggan, berkomunikasi secara berkala dan berkelanjutan. Saat ketidakpastian dari pelanggan berkurang sehingga pelanggan percaya untuk menggunakan akomodasi dan pelayanan yang ditawarkan sales dan marketing maka diperoleh penilaian dari pelanggan. Penilaian pelanggan sangat penting untuk membangun kepercayaan untuk calon pelanggan yang akan berkunjung. Berikut data hasil penilaian pelanggan yang bersumber dari website Holiday Inn Resort Bali Benoa. 
Gambar 2

Review of Staff. Comfortable, Value, Cleanliness, $F \& B$, Able to Relax Holiday Inn Resort Bali Benoa

\begin{tabular}{lccccc}
\hline \multicolumn{5}{c}{ Month } & \multicolumn{5}{c}{ Staff. Comfortable, Value, Cleanliness, } \\
& Excellent & Very Good & Good & Bad & Very Bad \\
\hline January & $90,1 \%$ & $9,9 \%$ & $0 \%$ & $0 \%$ & $0 \%$ \\
February & $66,7 \%$ & $22,2 \%$ & $11,1 \%$ & $0 \%$ & $0 \%$ \\
March & $75 \%$ & $12,5 \%$ & $8,3 \%$ & $4,2 \%$ & $0 \%$ \\
April & $87,1 \%$ & $12,9 \%$ & $0 \%$ & $0 \%$ & $0 \%$ \\
May & $80,8 \%$ & $15,3 \%$ & $3,9 \%$ & $0 \%$ & $0 \%$ \\
June & $80 \%$ & $20 \%$ & $0 \%$ & $0 \%$ & $0 \%$ \\
July & $69,6 \%$ & $21,8 \%$ & $4,3 \%$ & $4,3 \%$ & $0 \%$ \\
August & $84,6 \%$ & $15,4 \%$ & $0 \%$ & $0 \%$ & $0 \%$ \\
September & $76,7 \%$ & $20 \%$ & $3,3 \%$ & $0 \%$ & $0 \%$ \\
October & $88 \%$ & $8 \%$ & $4 \%$ & $0 \%$ & $0 \%$ \\
November & $88,8 \%$ & $5,6 \%$ & $5,6 \%$ & $0 \%$ & $0 \%$ \\
December & $76,2 \%$ & $14,3 \%$ & $4,8 \%$ & $0 \%$ & $4,7 \%$ \\
\hline \multicolumn{1}{c}{ Total } & $80.30 \%$ & $14,82 \%$ & $3,78 \%$ & $0,70 \%$ & $0.40 \%$ \\
\hline
\end{tabular}

Sumber: Data diolah Peneliti Berdasarkan Review Website 2019

Data hasil penilain pelanggan review yang selalu ditanggapi oleh pelanggan yang sudah pernah menginap di Holiday Inn Resort Bali Benoa. Terkait dengan karyawan, kenyamanan, harga, kebersihan, pelayanan makanan dan minunam, serta ketenangan dari Holiday Inn Resort Bali Benoa, dapat dilihat bahwa tamu yang menginap pada tahun 2019 memberikan penilaian bahwa pada hotel ini terkait dengan fasilitas dan pelayanan pelanggan memberikan penilaian excellent dengan skor $80.30 \%$ dan very good sebesar 14,82 \%. Hasil ini membuktikan bahwa Holiday Inn Resort Bali Benoa mendapatkan tanggapan atau umpan balik yang sangat positif dari pelanggan. Sehingga hotel ini dapat direkomendasikan kepada keluarga yang ingin berlibur ke Bali khususnya kawasan Nusa Dua.

Kepercayaan pelanggan kepada Holiday Inn Resort Bali Benoa menghantarkan resor ini memperoleh pengghargaan yaitu Tri Hita Karana Tourism Award 2019 yang menunjukkan resor ini memiliki kesan dan citra baik di masyarakat. Umat Hindu di Bali mengimplementasikan konsep Tri Hita Karana untuk menyelaraskan hidup dan menciptakan keharmonisan. Hubungan manusia dengan Tuhan (parahyangan), hubungan manusia dengan manusia (pawongan), dan hubungan manusia dengan alam sekitar (palemahan) telah diterapkan oleh Holiday Inn Resort Bali Benoa.

Kesinambungan pihak manajemen dalam menjaga reputasi Holiday Inn Resort Bali Benoa, sales dan marketing bekerja sama dengan divisi lainnya untuk memberikan pelayanan khusus bagi yang memiliki permintaan tertentu. Umpan balik dari pelanggan biasanya ditanggapi langsung oleh General Manager Holiday Inn Resort Bali Benoa, Adanya review memudahkan sales dan marketing menyusun rencana-rencana penawaran sesuai keinginan dari calon pelanggan nantinya yang akan menginap kembali ke hotel. Adanya indikator yang mendukung seperti kepercayaan pelanggan, minat dan permintaan pelanggan, kecocokan harga yang pelanggan inginkan, kelengkapan sarana dan prasarana hotel, dan kerja sama yang erat pihak menejemen Holiday Inn Resort Bali Benoa yang memiliki tujuan membangun citra baik perusahaan jangka panjang agar tercipta repeater guest.

Peningkatan penjualan oleh saled dan marketing dilakukan dengan komunikasi 
pemasaran yang dilakukan dengan cara sebagai berikut:

1. Advertising (periklanan) yaitu pemasaran melalui iklan yang terdapat pada sosial media seperti facebook dengan meningkatkan kualitas visual dan audio agar pelanggan dapat tertarik dengan iklan penawaran yang diberikan seperti iklan facebook kids stay \& eat free.

2. Sales Promotion atau promosi penjualan dengan mempersiapkan dan merancang penawaran dalam jangka waktu tertentu seperti stay one night get one free atau menginap semalam gratis menginap semalam.

3. Public relations and publicity atau hubungan masyarakat. Holiday Inn Resort Bali Benoa telah bekerja sama dengan organisasi PHRI (Perhimpunan Hotel da Restoran Indonesia) telah memberikan bantuan berupa sembako pada Bulan Mei 2020 kepada masyarakat yang terkena dampak wabah Covid-19.

4. Personal Selling atau penjualan perorangan yaitu sales dan marketing memberikan presentasi terkait dengan penawaran yang dimiliki seperti paket akomodasi dan paket acara pernikahan dengan cara table top atau bertatap muka dan melalui media sosial seperti instagram, facebook, twitte dan email Holiday Inn Resort Bali Benoa. Melakukan presentasi kerjasama dengan agen perjalanan wisata seperti TUI Destimo, Asia Eacape Holiday, MG Holiday, Flight Center, Mandira Bali, HOORO Australia serta bekerja sama dengan British Airways.

Komunikasi pemasaran yang dilakukan tidak lepas dari penilaian dari pelanggan terkait dengan cara sales dan marketing memasarkan penawaran yang ada. Adapun kelebihan sales dan markeiing Holiday Inn Resort Bali Benoa menurut pelanggan yang pernah berkunjung yang diperoleh dari hasil wawancara adalah sales dan marketing dapat menjelaskan secara detail penawaran yang diberikan sehingga memudahkan pelanggan untuk mengerti dan menangkap maksud dari yang disampaikan dan dari keseluruhan kualitas pelayanan manajemen Holiday Inn Resort Bali Benoa dinilai baik oleh pelanggan yang pernah berkunjung. Penilaiaan positif ini menghasilkan kunjungan kembali ke Holiday Inn Resort Bali Benoa atau repeater guest. Namun terdapat kelemahan sales dan marketing yaitu kurang dapat bernegosiasi.

\section{SIMPULAN}

Berdasarkan hasil pembahasan strategi komunikasi interpersonal dan komunikasi pemasaran yang dilakukan sales dan marketing Holiday Inn Resort Bali Benoa dapat disimpulkan:

1. Terdapat perencanaan komunikasi yang telah dilakukan sales dan marketing Holiday Inn Resort Bali Benoa seperti visi menciptakan kenangan bagi pelanggan sebagai tujuan dalam pemasaran, melakukan briefing untuk menentukan penawaran yang akan diberikan kepada pelanggan dengan melihat segmentasi pasar dan target pasar yang dicapai, penggunaan Bahasa Indonesia dan Bahasa Inggris dalam memberikan penawaran yang bersifat persuasif, serta meningkatkan kualitas produk yang dimiliki oleh Holiday Inn Resort Bali Benoa untuk memenuhi minat pasar wisatawan domestik dan asing seluruh dunia (Eropa, Amerika, Afrika, Asia dan Australia).

2. Untuk mengatasi ketidakpastian sales dan marketing Holiday Inn Resort Bali Benoa melakukan beberapa strategi seperti startegi pasif yaitu mengamati pelanggan yang akan menjadi target sasaran penjualan seperti mengamati melalui informasi di internet, strategi aktif yaitu dengan melihat kondisi pasar dengan mencari tahu lebih banyak infromasi kebutuhan pelanggan serta

3. Komunikasi pemasaran yang diterapkan oleh sales dan marketing Holiday Inn Resort Bali Benoa adalah

a. Dengan mempersiapkan dan mengiklankan produk yang dimiliki melalui sosial media seperti facebook, instagram, dan twitter,

b. promosi penjualan dengan mempersiapkan penawaran dan memberikan promosi jangka pendek kepada pelanggan,

c. meningkatkan hubungan masyarakat Holiday Inn Resort Bali Benoa bekerja sama dengan salah satu organisasi Perhimpunan Hotel dan Restoran Indonesia cabang Bali atau yang biasa 
disebut (PHRI) untuk meningkatkan citra positif di mata masyarakat luas,

d. penjualan perorangan yaitu mempersiapkan kualitas penawaran yang akan diberikan oleh sales dan marketing kepada pelanggan dengan menggunakan cara table top di pameran-pameran, serta melakukan penjualan kepada agen perjalanan wisata seperti TUI Destimo, Asia Eacape Holiday, MG Holiday, Flight Center, Mandira Bali, HOORO Australia serta bekerja sama dengan British Airways

4. Kelebihan sales dan markeiing Holiday Inn Resort Bali Benoa adalah dapat menjelaskan secara detail penawaran yang diberikan sehingga memudahkan pelanggan untuk mengerti dan menangkap maksud dari yang disampaikan dan dari keseluruhan kualitas pelayanan manajemen Holiday Inn Resort Bali Benoa dinilai baik oleh pelanggan yang pernah berkunjung.

5. Kelemahan sales dan markeiing Holiday Inn Resort Bali Benoa adalah kurang dapatnya bernegosisasi dengan baik dengan pelanggan.

\section{SARAN}

Berdasarkan hasil dari pembahasan maka saran untuk meningkatkan kunjungan pelanggan adalah sebagai berikut:

1. Agar pihak sales dan marketing Holiday Inn Resort Bali Benoa dapat menerapkan seluruh strategi komunikasi interpersonal dengan kualitas penawaran yang baik serta menggunakan strategi pengurangan ketidakpastian untuk menagatasi masalah keraguan pelanggan mengambil sebuah penawaran.

2. Sales dan marketing Holiday Inn Resort Bali Benoa dapat bernegosiasi dengan baik saat memberikan penawaran kepada pelanggan

3. Sales dan marketing sebaiknya memperbarui penawaran-penawaran yang ada agar promosi menjadi bervariasi sehingga meningkatkan minat pelanggan dalam menggunakan penawaran yang ada.

4. Untuk pihak manajemen Holiday Inn Resort Bali Benoa meningkatkan pelayanan prima dalam melayani tamu terutama dalam memasarkan penawaran-penawaran khusus terutama yang paling diminati yaitu leisure dan wedding dan penawaran khusus lainnya. Mengemas seluruh penawaran dengan bahasa yang menarik dan lebih efektif dalam memasarkan akomodasi dan layanan lainnya.

5. Sales dan marketing agar lebih banyak mempersiapkan paket promo dengan harga harga yang dapat dijangkau terutama promo yang dimati pelanggan yaitu leisure dan wedding.

\section{DAFTAR PUSTAKA}

Agus Pranata dkk. 2017. Penerapan Konsep Tri Hita Karana di The Trans Resort Bali. Jurnal Pariwisata Universitas Udayana. Vol. 1, No. 1, Hal. 10.

Badan Pusat Statistik. 2020. Perkembangan Pariwisata Provinsi Bali Januari 2020. https://badungkab.bps.go.id/pressrelease /2020/03/03/215/perkembanganpariwisata-provinsi-bali-januari-

2020.html. Diaskses pada tanggal 10 Maret 2020.

Budyatna, Muhammad. 2015. Teori-Teori Mengenai Komunikasi Antar Pribadi.

Jakarta: Prenada Media Group.

Intan, Norvica. 2018. Perencanaan Komunikasi Interpersonal Yayasan Sosial dalam Membangun Kepercayaan Donatur. Univ. Islam Negeri Sunan Kalijaga Yogyakarta.

Litllejohn, Stephen. 2009. Teori Komunikasi (Theories of Human Communication). Jakarta: Salemba Humanika.

Moleong, Lexy. 2005. Metodologi Penelitian Kualitatif. Bandung: PT Remaja Rosdakarya.

Sugiyono. 2008. Metode Penelitian Kuantitatif Kualitatif dan R\&D. Bandung: Alfabeta.

Suhardi, Untung dan Wayan Tantre. 2018. Etika Komunikasi dalam Veda (Tinjauan Fenomenologi Pada Era Globalisasi). Jurnal Pasupati. Vol. 5 No. 1, Hal. 63-75

Suranto, A. 2011. Komunikasi Interpersonal. Yogyakarta: Graha Ilmu. 